\title{
Does flooring-type change the gait characteristics of the older adult? Analysis of balance and temporal-spatial gait parameters and ground reaction force
}

\author{
Ganokroj P1, Limroongreungrat $W^{3}$, Kerdsomnuek P², Riansuwan $\mathrm{K}^{1}$, Keyurapan $\mathrm{E}^{1}$, Wang $\mathrm{YT}^{2}$ and Vanadurongwan $\mathrm{B}^{1 *}$ \\ ${ }^{1}$ Department of Orthopaedic Surgery, Faculty of Medicine Siriraj Hospital, Mahidol University, Bangkok, Thailand \\ ${ }^{2}$ School of Nursing, College of Nursing and Health Sciences, the University of Texas at Tyler, USA \\ ${ }^{3}$ College of Sports Science and Technology, Mahidol University, Bangkok, Thailand
}

${ }^{*}$ Correspondence to: Bavornrat Vanadurongwan, Department of Orthopaedic Surgery Faculty of Medicine Siriraj Hospital, Mahidol University, 2 Prannok Road, Bangkoknoi, Bangkok 10700, Thailand; E-mail: bavornrat@gmail.com

Received: September 23, 2018; Accepted: September 28, 2018; Published: October 02, 2018;

\begin{abstract}
Introduction: Slips, trips and loss of balance were the major causes of fall in older adult. The study aimed to compare the balance, temporal-spatial gait parameters and ground reaction forces of compliant, rubber and standard flooring.

Materials and Methods: Sixty-four healthy, elderly people were assessed between July 2016 and December 2017. Eight optoelectronic cameras were used to measure the centers of mass (COM) of the body during gait: the velocity, the lowest position, and medio-lateral and vertical COM displacements. We also compared the temporal-spatial gait parameters, vertical ground reaction force (GRF), and anterior-posterior GRF of the three flooring types.

Results: The step widths of the gait on the compliant and rubber floorings were significantly narrower than that of the standard flooring $(p=0.005$ and 0.032 , respectively). The COM velocity of the compliant flooring was higher than that of the rubber flooring $(p=0.03)$. There were no differences in the lowest COM positions, or in the medio-lateral and vertical COM displacements. There were significant increases in the peak posterior and anterior GRFs for the standard flooring with comparison to the compliant and rubber floorings $(p<0.001)$.

Conclusion: Compared with the rubber and standard flooring, the compliant flooring displayed no differences in balance and stability for older adult people in both the vertical and antero-posterior planes. For both legs, there was less vertical GRF at the toe-off phase and less anterior-posterior GRF with the compliant flooring. The selected compliant flooring may be a safe instrument that can be used to adjust the environmental factor in order to prevent falls.
\end{abstract}

Trial registration number TCTR2018-0211001, approved for registration at TCTR since 2018-02-06; and retrospectively registered.

Keywords: Flooring type, gait characteristics, balance, temporal-spatial gait parameters, ground reaction force, elderly

\section{Introduction}

A fall is an unintentional loss of balance, causing unprepared contact with the ground or the floor. Approximately $28 \%-35 \%$ of people aged 65 or over fall each year [1-3], with the figure increasing to $32 \%-42 \%$ for those over 70 [4-6]. The frequency of falls increases with age and frailty level. Assantachai et al. found that the overall prevalence of falls among elderly Thais in urban areas was $19.8 \%$ over a six-month period [7]. Falls and their consequential injuries are major public health problems that often require medical attention. The fall fatality rate varies, depending on the country or the culture of the population.

Many factors are considered to increase the risk of falls. Environmental factors are one of the four major risks of falls (biological, behavioral, socioeconomic, and environmental) identified in a WHO global report [8]. Compliant flooring was introduced with the aim of reducing the risk of falls among the older adult. A recent scoping review protocol suggested that compliant flooring would reduce the incidence of fall-related injuries $[9,10]$. Although some studies have demonstrated that compliant flooring may increase the risk of falls by older adults [11], other studies did not find evidence in support of that finding $[12,13]$. From biomechanical efficacy records, compliant flooring may reduce the fall-related impact forces with a minimal effect on standing and walking balance [10]. However, the safety and balance effects when walking on compliant flooring compared with on rubber or standard flooring have not yet been documented. For this reason, it was decided to study the dynamics of balance, temporal-spatial gait parameters, and ground reaction forces of specific compliant flooring compared with rubber and standard flooring for healthy, older adult people. 


\section{Materials and methods}

\section{Study design}

An experimental design was conducted with the approval of the Institutional Review Board of our hospital. It was approved for registration at the Thai Clinical Trials Registry (http://www. clinicaltrials.in.th; registration number TCTR20180211001). This experimental design followed the TIDieR checklist (Additional file 1) [14].

\section{Participants}

Sixty-four older adult people were recruited for this study. Prior to its commencement, all participants read an information sheet and signed an informed consent form that had been approved by the Human Research Protection Unit of our hospital. Patients who refused to participate or who had any discomfort during the study were able to withdraw. The inclusion criteria were participants aged 60 years or older between July 2016 and December 2017. The study included healthy, the older adult people who had not had any falls in the year preceding the study, and who did not have any walking problems. Excluded were patients who had bone disease, muscular disease, pain anywhere on their body that exceeded a score of 4 on a 10-point VAS (visual analogue scale) pain scale and affected their walking pattern, or a history of lower extremity surgery in the 6 months prior to the study.
The results of this study will be released to the healthcare community. Datasets or statistical codes will not be made public. The results of the study will be disseminated to study participants by means of lectures given by the investigators.

\section{Intervention}

\section{Compliant flooring}

This study used a multilayered flooring ( $10 \mathrm{~m}$ long, $2 \mathrm{~m}$ wide, and $0.003 \mathrm{~m}$ deep), with a stiffness of $19.17 \mathrm{kN} / \mathrm{m}$. After studying the test methods used to measure the shock absorption properties of indoorsports flooring materials, we designed our own protocol (the "ball bounce method") to compare the relative shock absorption of the tested materials. With that method, a solid metal ball (stainless steel; $5 \mathrm{~cm}$ diameter) weighing $258 \mathrm{~g}$ is dropped from a height of $200 \mathrm{~cm}$ onto a $20 \mathrm{~cm} \times 20 \mathrm{~cm}$ piece of tested material that has been securely installed on a concrete floor. The rebound height is simultaneously recorded using a video camera (10 MP, $60 \mathrm{fps}$ ), and 3 repetitions are averaged.

The selected compliant flooring (Figure 1), the Unix Ultimate Oak (SCG Cement-Building Materials, BK, THA), http://www. sjsourcing.com/products?id=4, can absorb a force of around 30\% with a coefficient of restitution (COR) of $0.83[15,16]$. The comparison flooring in this study was rubber flooring (Figure 1) with a COR of 0.92 and standard flooring (a rigid force plate) (Figure 2).

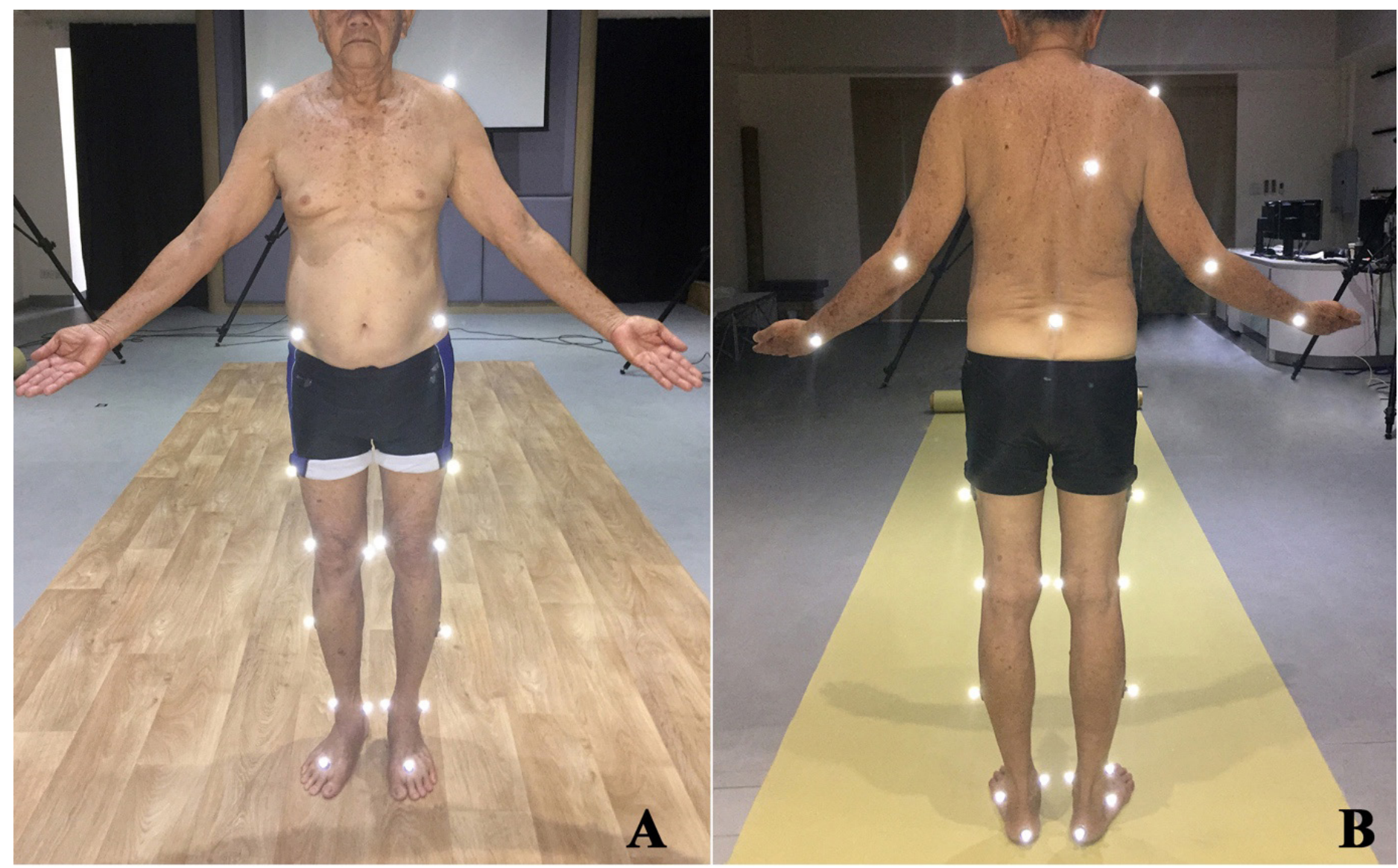

Figure 1. (A) Front view of the 29 reflective markers that were applied on the body. Patients was standing on the compliant flooring. (B) Back view of the patients with the reflective markers. Patients was standing on the rubber flooring. 


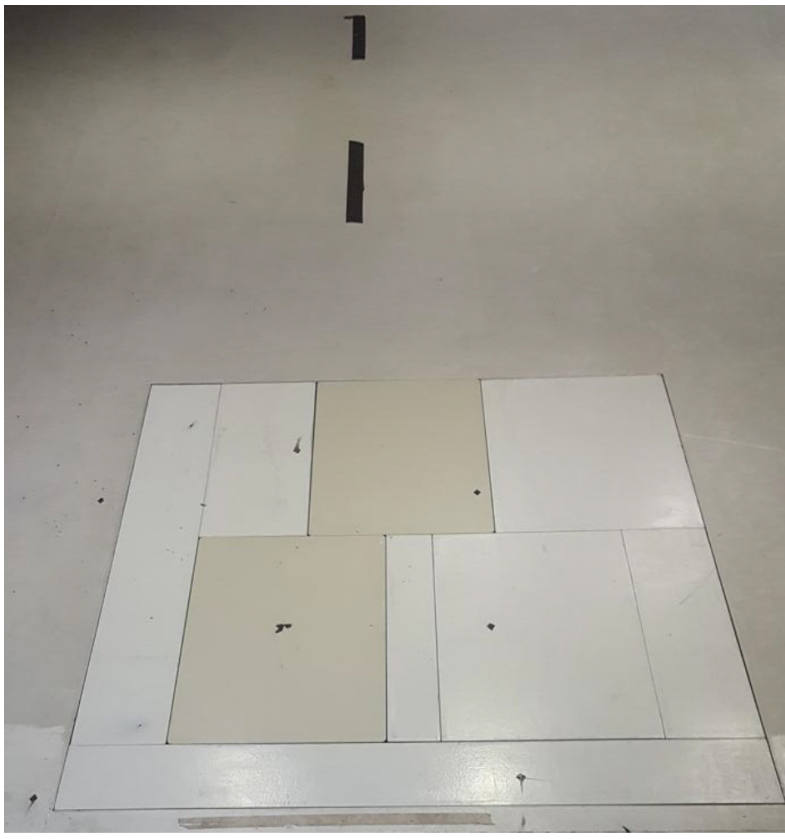

Figure 2. The rigid force plate and the standard flooring type

\section{Protocol}

Eight optoelectronic cameras (Motion Analysis Corp., Santa Rosa, CA, USA) were used to record three-dimensional kinematic data at a sampling rate of $200 \mathrm{~Hz}$. Twenty-nine reflective markers were placed bilaterally on anatomical landmarks, as illustrated at Figure 1. This enabled the construction of 12 segments to fully estimate the body center of mass (COM) [17]. Two force platforms (ATMI, Watertown, MA, USA), used to measure the ground reaction force at a sampling rate of $1600 \mathrm{~Hz}$, were synchronized with the motion analysis cameras. Data relating to the participants walking on the three types of flooring were collected. All participants were conducted at our motion analysis laboratory facility.

Participants walked on a 10-meter walkway of each flooring at a self-comfortable speed; the walk was repeated 5 times for each flooring type. A successful trial was defined as one in which all parts of the foot contacted the force platform surface during each step, and in which no marker fell off during data collection. The study measurement was conducted by PG who was the sports medicine orthopedics doctor and $\mathrm{PK}$ who was specialized in motion gait analysis.

\section{Data analysis}

Kinematic data were filtered using a Butterworth low-pass filter with a cut-off frequency of $6 \mathrm{~Hz}$ [18]. Orthotrak software, version 6.6 (Motion Analysis Corp., Santa Rosa, CA, USA) was used to analyze the temporal-spatial gait parameters of gait velocity, step width, and step length. The gait velocity was defined as the speed of the center of mass in a forward direction. Step width was determined by the distance between the ankles' joint centers in a medio-lateral line. Step length was defined as the heel-marker distance between one foot as it contacted the ground, and the other foot as it touched the ground at the same instant of time.
Cortex software, version 3.1 (Motion Analysis Corp., Santa Rosa, CA, USA) was used to analyze the dynamic balance while walking, as indicated by the displacement of the COM in the vertical and mediolateral directions. The vertical COM displacement was represented by the difference between the maximum COM position and the minimum, or lowest, COM position in the vertical direction. The medio-lateral COM displacement was the maximum COM position minus the minimum COM position in the medio-lateral direction [19].

The ground reaction forces (GRF) in the vertical and anteroposterior directions were analyzed using the Orthotrak software. The characteristics of the following gait events were examined: 1) when the foot contacted the ground in the loading response phase (vertical GRF exceeded $30 \mathrm{~N}$ ); 2) when the vertical GRF was at its first peak in the loading response phase; 3 ) when the vertical GRF was at its second peak in the terminal stance phase; and 4) at the toe-off phase. Leg dominance was determined using this self-reported question: "If you kicked a ball at a target, which leg would you use to kick the ball?” [20].

\section{Sample size estimation}

$\mathrm{G}^{\star}$ Power, version 3.1, [21] was used to determine the adequate sample size. The estimated sample size was calculated based on the primary outcome, the COM displacement, using a one-way repeated measures ANOVA. It was decided to arbitrarily select a moderate treatment effect. To detect the effect size (Cohen $\mathrm{f}=0.175)$ with an 0.7 correlation among 3 repeated measures, $90 \%$ power of test and a $5 \%$ type I error, a minimum of 42 participants were needed for this study.

\section{Statistical analysis}

All Statistical analysis were performed using SPSS Statistics for Windows, version 18.0 (SPSS Inc., Chicago, IL, USA). Firstly, data were evaluated for normality using Shapiro-Wilk's test and a histogram plot with a normal curve. Descriptive statistics were used to summarize the demographic data and motion analysis measurements, including the temporal-spatial gait parameters. The mean and standard deviation (mean $\pm \mathrm{SD}$ ) were calculated for the quantitative variables, while absolute frequency and percentage were determined for the categorical variables. One-way repeated measures ANOVA was used to establish the differences in the gait characteristics and GRFs of the three flooring conditions. Bonferroni's test was employed for a posthoc analysis. The dominant and non-dominant legs were analyzed separately to avoid producing a bimodal distribution influencing normality. The statistically significant level was set at 0.05 .

\section{Results}

There were 64 elderly people ( 38 females and 26 males), with a mean age of $67.2 \pm 4.4$ years, a mean weight of $56.0 \pm 9.6 \mathrm{~kg}$, and a mean height of $158.0 \pm 8.0 \mathrm{~cm}$.

\section{Temporal-spatial parameters}

The temporal-spatial parameters during walking on the three flooring types are in Table 1. The step width of the compliant and rubber flooring were significantly narrower than that of the standard flooring ( $p=0.005$ and 0.032 , respectively; Figure 3A). The step length (non-dominant leg) while walking on the rubber flooring was 
significantly shorter than that for the compliant and standard flooring ( $p<0.001$ and 0.035 , respectively; Figure. 3B). The gait velocity and

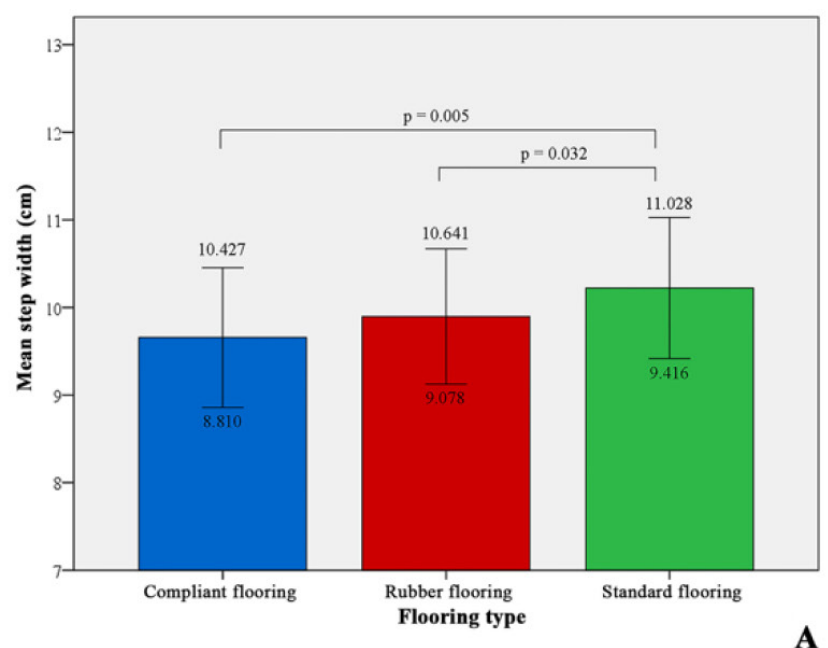

step length of the dominant leg were not significantly different for the three flooring types.

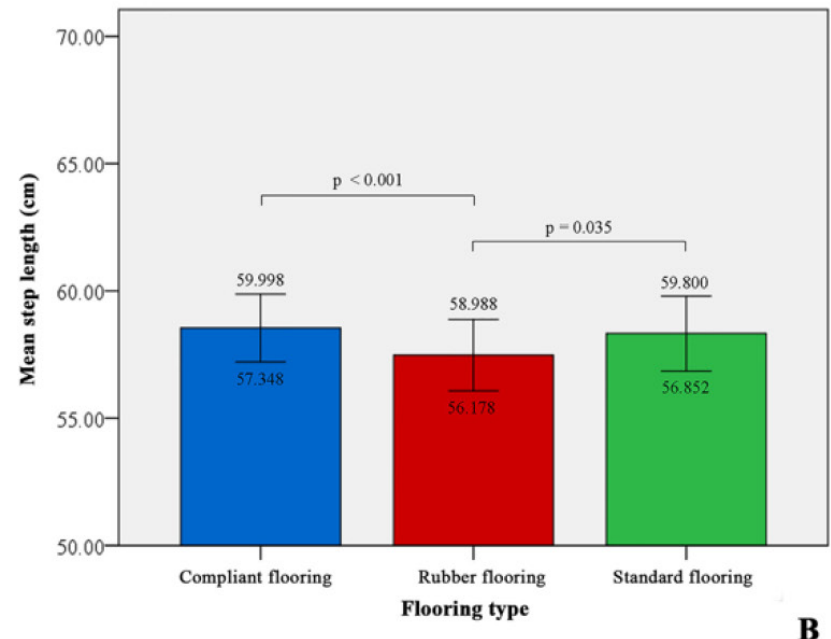

Figure 3. Comparison between flooring types of step width and length (non-dominant leg):

Comparison between flooring types using Bonferroni's test. (A) for step width and (B) for step length of the non-dominant leg (error bar $=95 \% \mathrm{CI}$ for mean). ( $\mathrm{cm}$ ) The blue bar is for compliant flooring, the red bar for rubber flooring and the green bar for standard flooring. The statistically significant level was set at 0.05 .

\section{Center of mass movement}

The center of mass movement defined the dynamic balance of the patients. The movement of the COM variables during walking on the three flooring types are in Table 2. Although the COM velocity of the compliant flooring was significantly higher than that for the rubber flooring, with 108.64 and $106.74 \mathrm{~cm} / \mathrm{s}$, respectively $(p=0.03$; Figure 4), it was not significantly different to that for the standard flooring. There were no differences in the minimum positions of the COM, the medio-lateral displacements, and the COM vertical displacements of the three flooring types.

Table 1. Temporal-spatial parameters of walking on the compliant, rubber and standard flooring.

\begin{tabular}{|c|c|c|c|c|}
\hline Variable & $\begin{array}{c}\text { Compliant } \\
\text { flooring } \\
\text { (Mean } \pm \\
\text { SD) }\end{array}$ & $\begin{array}{c}\text { Rubber } \\
\text { flooring } \\
\text { (Mean } \pm \\
\text { SD) }\end{array}$ & $\begin{array}{c}\text { Standard } \\
\text { flooring } \\
\text { (Mean } \pm \\
\text { SD) }\end{array}$ & P-value \\
\hline Step width $(\mathrm{cm})$ & $\begin{array}{l}9.65 \pm \\
3.09^{\# 1}\end{array}$ & $\begin{array}{l}9.89 \pm \\
2.98^{\# 2}\end{array}$ & $\begin{array}{l}10.22 \pm \\
3.09^{\# 1, \# 2}\end{array}$ & 0.002 \\
\hline $\begin{array}{l}\text { Velocity of dominant } \\
\text { leg }(\mathrm{cm} / \mathrm{s})\end{array}$ & $\begin{array}{c}108.74 \pm \\
11.78\end{array}$ & $\begin{array}{c}107.18 \pm \\
12.72\end{array}$ & $\begin{array}{c}108.68 \pm \\
14.31\end{array}$ & 0.207 \\
\hline $\begin{array}{l}\text { Velocity of non- } \\
\text { dominant leg }(\mathrm{cm} / \mathrm{s})\end{array}$ & $\begin{array}{c}108.63 \pm \\
11.61\end{array}$ & $\begin{array}{c}106.93 \pm \\
12.61\end{array}$ & $\begin{array}{c}108.51 \pm \\
14.38\end{array}$ & 0.145 \\
\hline $\begin{array}{l}\text { Step length of } \\
\text { dominant leg }(\mathrm{cm})\end{array}$ & $\begin{array}{c}57.82 \pm \\
4.96\end{array}$ & $\begin{array}{c}57.16 \pm \\
5.12\end{array}$ & $\begin{array}{l}56.99 \pm \\
5.29\end{array}$ & 0.100 \\
\hline $\begin{array}{l}\text { Step length of non- } \\
\text { dominant leg }(\mathrm{cm})\end{array}$ & $\begin{array}{c}58.54 \pm \\
5.14^{\# 3}\end{array}$ & $\begin{array}{c}57.47 \pm \\
5.41^{\# 2}\end{array}$ & $\begin{array}{c}58.32 \pm \\
5.65^{\# 2, \# 3}\end{array}$ & $<0.001$ \\
\hline
\end{tabular}

\#1 Standard flooring VS Compliant flooring

\#2 Standard flooring VS Rubber flooring

\#3 Compliant flooring VS Rubber flooring
Table 2. Movement of the center of mass variables.

\begin{tabular}{|l|c|c|c|c|}
\hline \multicolumn{1}{|c|}{ Variable } & $\begin{array}{c}\text { Compliant } \\
\text { flooring } \\
\text { (Mean } \pm \\
\text { SD) }\end{array}$ & $\begin{array}{c}\text { Rubber } \\
\text { flooring } \\
\text { (Mean } \pm \\
\text { SD) }\end{array}$ & $\begin{array}{c}\text { Standard } \\
\text { flooring } \\
\text { (Mean } \pm \\
\text { SD) }\end{array}$ & P-value \\
\hline COM velocity $(\mathrm{cm} / \mathrm{s})$ & $\begin{array}{c}108.64 \pm \\
11.65 \text { \#3 }\end{array}$ & $\begin{array}{c}106.74 \pm \\
12.65\end{array}$ & $\begin{array}{c}108.36 \pm \\
14.33\end{array}$ & 0.040 \\
\hline $\begin{array}{l}\text { COM minimum } \\
\text { position }(\mathrm{cm})\end{array}$ & $\begin{array}{c}79.76 \pm \\
11.30\end{array}$ & $\begin{array}{c}79.97 \pm \\
11.14\end{array}$ & $\begin{array}{c}74.74 \pm \\
22.34\end{array}$ & 0.066 \\
\hline $\begin{array}{l}\text { COM medio-lateral } \\
\text { displacement }(\mathrm{cm})\end{array}$ & $3.38 \pm 1.30$ & $3.43 \pm 1.23$ & $3.18 \pm 1.68$ & 0.132 \\
\hline $\begin{array}{l}\text { COM vertical } \\
\text { displacement }(\mathrm{cm})\end{array}$ & $2.45 \pm 0.59$ & $2.37 \pm 0.57$ & $2.34 \pm 0.89$ & 0.212 \\
\hline
\end{tabular}

$\mathrm{COM}=$ center of mass

\#1 Standard flooring VS Compliant flooring

\#2 Standard flooring VS Rubber flooring

\#3 Compliant flooring VS Rubber flooring

\section{Vertical ground reaction force}

The vertical ground reaction force (VGRF) of both the dominant and non-dominant legs walking on the three flooring types are in Table 3. There was a reduction in the VGRF at the toe-off phase to the compliant and rubber flooring compared to the standard flooring for both the dominant and non-dominant legs ( $p=0.005$ and $<0.001$, respectively; Figure 5). There were no differences in the VGRFs at the initial contact, loading response (first peak) and the second peak VGRF while walking on the three flooring types (Figure 6). 


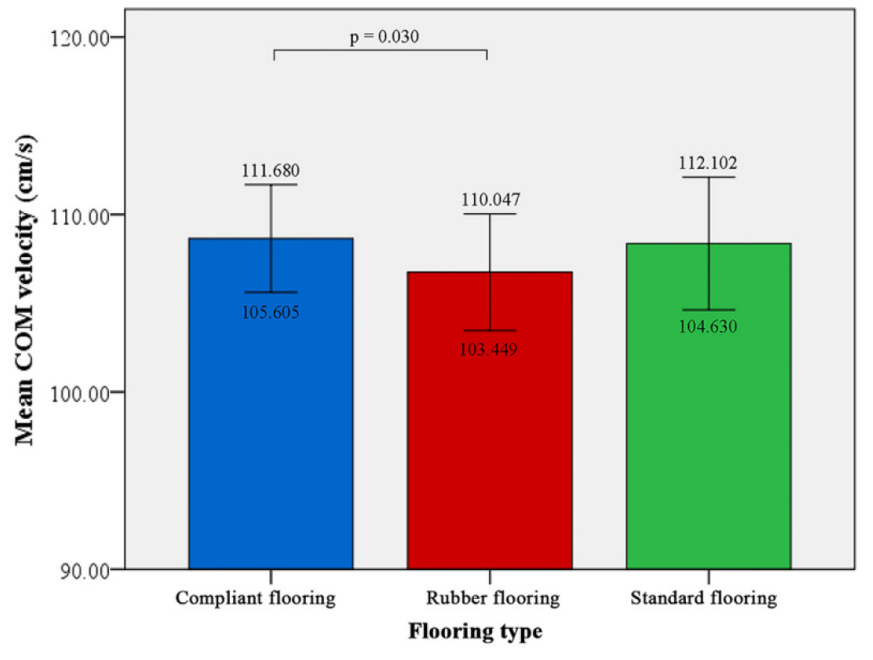

Figure 4. Comparison between flooring types of COM velocity.

Comparison between flooring types using Bonferroni's test for center of mass (COM) velocity (error bar $=95 \%$ CI for mean). $(\mathrm{cm} / \mathrm{s})$ The blue bar is for compliant flooring, the red bar for rubber flooring and the green bar for standard flooring. The statistically significant level was set at 0.05 .

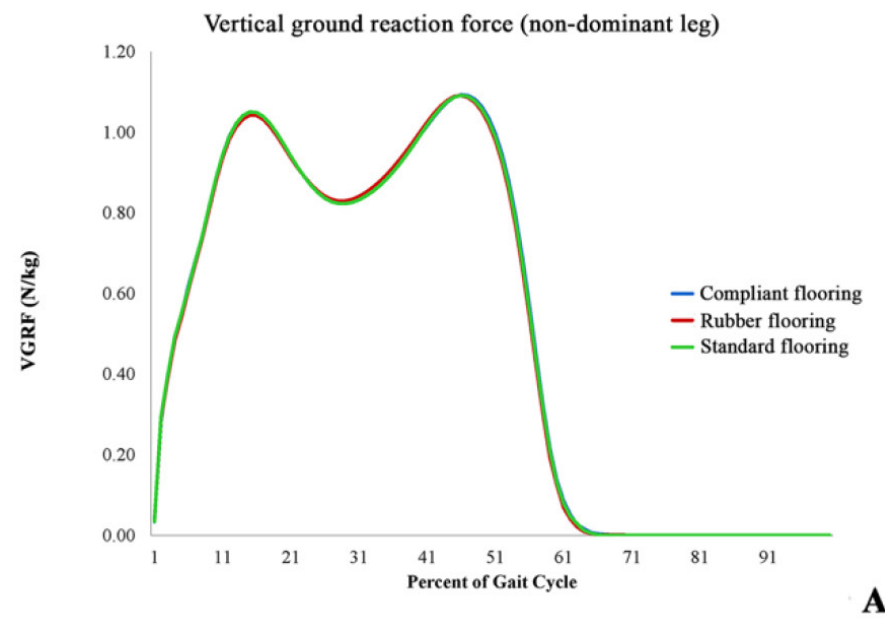

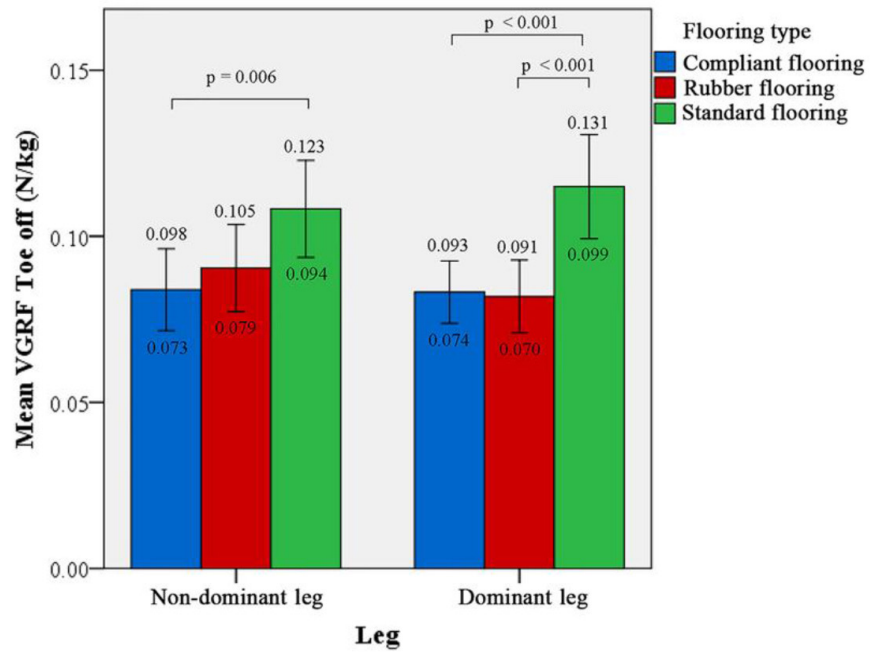

Figure 5. Comparison between flooring types of VGRF (toe-off phase).

Comparison between flooring types using Bonferroni's test for vertical ground reaction force (GRF) at toe-off phase (error bar $=95 \%$ CI for mean). (N/kg) The blue bar is for compliant flooring, the red bar for rubber flooring and the green bar for standard flooring. The statistically significant level was set at 0.05 .

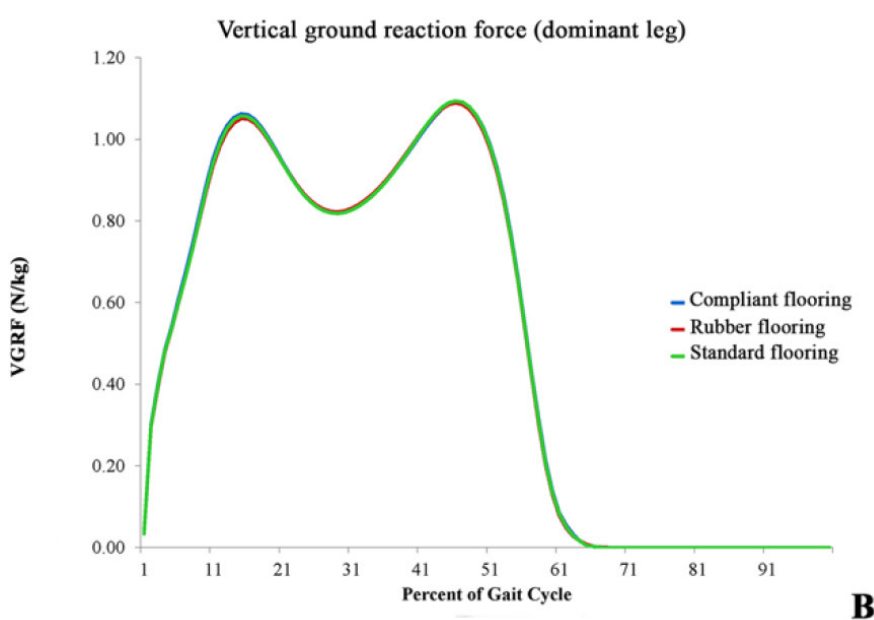

Figure 6. VGRF of the three flooring types:

Vertical ground reaction force (GRF) of the gait cycle for the three flooring types for the non-dominant leg (A) and the dominant leg (B). (N/kg) The blue line is for compliant flooring, the red line for rubber flooring and the green line for standard flooring.

\section{Anterior-posterior ground reaction force}

The anterior-posterior ground reaction force (APGRF) of both legs while walking on the three flooring types are in Table 4 . There was a significant increase in the peak posterior GRF for the standard flooring compared with the compliant and the rubber flooring, with $p$ $<0.001$ for both the dominant and non-dominant legs. As for the peak anterior GRF, there was also a significant increase for the standard flooring compared with that for the rubber and compliant flooring (Figure 7). 
Vanadurongwan B (2018) Does flooring-type change the gait characteristics of the older adult? Analysis of balance and temporal-spatial gait parameters and ground reaction force
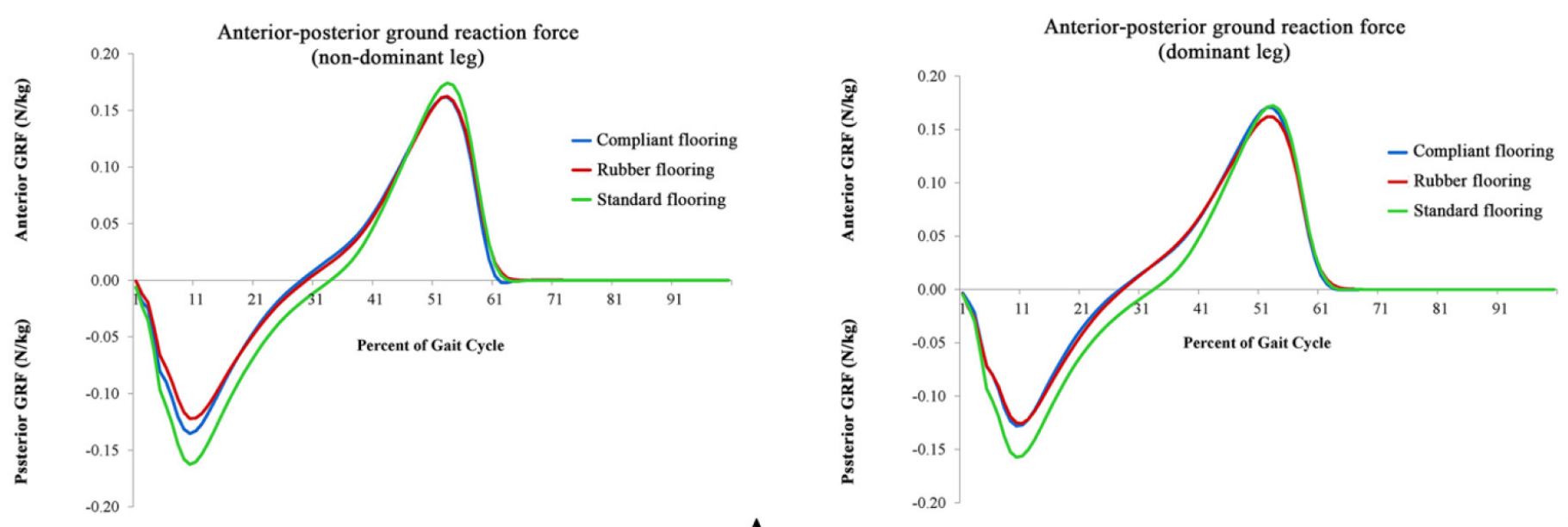

A

B

Figure 7. Anterior and posterior GRFs of the three flooring types:

Anterior and posterior ground reaction forces (GRFs) of the gait cycle for the three flooring types for the non-dominant leg (A) and the dominant leg (B). (N/kg) The blue line is for compliant flooring, the red line for rubber flooring and the green line for standard flooring.

Table 3 Vertical ground reaction force of both legs.

\begin{tabular}{|c|c|c|c|c|c|}
\hline Leg side & Event & $\begin{array}{l}\text { Compliant flooring } \\
(\text { Mean } \pm \text { SD) }\end{array}$ & $\begin{array}{l}\text { Rubber flooring } \\
(\text { Mean } \pm \text { SD })\end{array}$ & $\begin{array}{l}\text { Standard flooring } \\
\quad(\text { Mean } \pm \text { SD })\end{array}$ & $P$-value \\
\hline \multirow[t]{4}{*}{ Non-dominant leg } & Initial contact $(\mathrm{N} / \mathrm{kg})$ & $0.033 \pm 0.008$ & $0.034 \pm 0.008$ & $0.033 \pm 0.009$ & 0.339 \\
\hline & $\begin{array}{l}\text { Loading response (N/kg) } \\
\text { (First peak VGRF) }\end{array}$ & $1.079 \pm 0.075$ & $1.070 \pm 0.075$ & $1.077 \pm 0.081$ & 0.091 \\
\hline & $\begin{array}{l}\text { Terminal stance }(\mathrm{N} / \mathrm{kg} \text { ) } \\
\text { (Second peak VGRF) }\end{array}$ & $1.100 \pm 0.062$ & $1.098 \pm 0.067$ & $1.103 \pm 0.066$ & 0.546 \\
\hline & Toe off $(\mathrm{N} / \mathrm{kg})$ & $0.083 \pm 0.036^{\# 1}$ & $0.080 \pm 0.039$ & $0.114 \pm 0.059 \# 1$ & $<0.001$ \\
\hline \multirow[t]{4}{*}{ Dominant leg } & Initial contact $(\mathrm{N} / \mathrm{kg})$ & $0.033 \pm 0.008$ & $0.034 \pm 0.008$ & $0.034 \pm 0.008$ & 0.802 \\
\hline & $\begin{array}{l}\text { Loading response }(\mathrm{N} / \mathrm{kg}) \\
\text { (First peak VGRF) }\end{array}$ & $1.064 \pm 0.066$ & $1.058 \pm 0.066$ & $1.065 \pm 0.067$ & 0.237 \\
\hline & $\begin{array}{l}\text { Terminal stance }(\mathrm{N} / \mathrm{kg} \text { ) } \\
\text { (Second peak VGRF) }\end{array}$ & $1.102 \pm 0.058$ & $1.101 \pm 0.062$ & $1.102 \pm 0.062$ & 0.774 \\
\hline & Toe off $(\mathrm{N} / \mathrm{kg})$ & $0.085 \pm 0.047^{\# 1}$ & $0.092 \pm 0.051 \# 1$ & $0.108 \pm 0.055^{\# 1, \# 2}$ & 0.005 \\
\hline
\end{tabular}

$\mathrm{VGRF}=$ vertical ground reaction force

\#2 Standard flooring VS Rubber flooring

\#1 Standard flooring VS Compliant flooring \#3 Compliant flooring VS Rubber flooring

Table 4. Anterior-posterior ground reaction force of both legs.

\begin{tabular}{|c|c|c|c|c|c|}
\hline Leg side & Event & $\begin{array}{l}\text { Compliant flooring } \\
\quad(\text { Mean } \pm \text { SD })\end{array}$ & $\begin{array}{l}\text { Rubber flooring } \\
\text { (Mean } \pm \text { SD) }\end{array}$ & $\begin{array}{l}\text { Standard flooring } \\
\quad(\text { Mean } \pm \text { SD) }\end{array}$ & $P$-value \\
\hline \multirow[t]{2}{*}{ Non-dominant leg } & $\begin{array}{l}\text { Peak posterior }(\mathrm{N} / \mathrm{kg}) \\
\text { (Loading response) }\end{array}$ & $-0.13 \pm 0.02 \# 1, \# 3$ & $-0.12 \pm 0.02 \# 2, \# 3$ & $-0.15 \pm 0.03 \# 1, \# 2, \# 3$ & $<0.001$ \\
\hline & $\begin{array}{l}\text { Peak anterior }(\mathrm{N} / \mathrm{kg}) \\
\text { (Terminal stance) }\end{array}$ & $0.17 \pm 0.02 \# 1$ & $0.16 \pm 0.02$ \#2 & $0.17 \pm 0.02 \# 1, \# 2$ & $<0.001$ \\
\hline \multirow[t]{2}{*}{ Dominant leg } & $\begin{array}{l}\text { Peak posterior }(\mathrm{N} / \mathrm{kg}) \\
\text { (Loading response) }\end{array}$ & $-0.13 \pm 0.02 \# 1$ & $-0.12 \pm 0.02 \# 2$ & $-0.16 \pm 0.03 \# 1, \# 2$ & $<0.001$ \\
\hline & $\begin{array}{l}\text { Peak anterior }(\mathrm{N} / \mathrm{kg}) \text { (Terminal } \\
\text { stance) }\end{array}$ & $0.16 \pm 0.02 \# 3$ & $0.16 \pm 0.02^{\sharp 2, \# 3}$ & $0.17 \pm 0.03 \# 2$ & $<0.001$ \\
\hline
\end{tabular}

\#1 Standard flooring VS Compliant flooring

\#2 Standard flooring VS Rubber flooring

\#3 Compliant flooring VS Rubber flooring 


\section{Discussion}

Dynamic stability can be threatened by various travel surface changes, especially in the case of compliant surfaces. Adapting locomotor movements to the different types of surface encountered in daily life is essential. Many elderly people experience balance impairment, which is one of the major risks of falls [22-24]. With advancing age, there is a generalized reduction in visual function, which has been associated with impaired postural stability and an increased risk of falls.

Lord and Menz demonstrated that walking on a compliant surface increases the risk of falls by the elderly [25]. The vertical COM is decreased when stepping onto a compliant surface [26]. This adaptation of lowering the vertical COM peak provides a more stable posture. The lowering of the COM can also be seen in response to locomotion on a slippery surface in order to prevent a threat to instability [27]. However, the medio-lateral COM does not change when walking on a compliant surface [28]. The dynamic stability margin in the anteriorposterior direction demonstrates a constant overcompensation and subsequent correction of COM control. A scoping review of biomechanical efficacy found that the overall participants were able to maintain static and dynamic balance on carpet and on purposedesigned, novel compliant flooring (NCF) [10]. The present study also showed no statistically significant differences in the COM minimum positions, COM medio-lateral displacements, and COM vertical displacements of the three flooring types $(p>0.05)$. This may suggest good active regulation of the COM in both the frontal and sagittal plane while walking on both the compliant and the rubber flooring. Thus, the selected compliant flooring may not influence the balance and stability of elderly people in the vertical and horizontal planes.

There are 4 categories of compliant flooring: 1) thick vinyl; 2) carpet with no underlay; 3) NCF with no underlay or overlay; and 4) combination flooring [10]. In our study, the selected compliant flooring was categorized as a combination flooring with some shockabsorption properties. The rubber flooring was categorized as an NCF with no underlay or overlay. Consequently, the authors chose a rigid force for the standard flooring as the control group and aimed to compare it with different compliant flooring categories (categories 3 and 4). The authors found that there was more COM velocity with the compliant flooring than with the rubber flooring, but those velocities were not significantly different to that of the standard flooring. The results of this study indicate that there were no differences in the COM medio-lateral and vertical displacements of the three flooring types.

With increasing age, adults typically take shorter and wider steps [29]. Older people usually have more difficulty than younger adults maintaining balance while walking on irregular or uneven surfaces. Older people tend to adopt a more conservative walking pattern, characterized by a slower walking velocity and shorter steps to ensure trunk stability and maintain a stable gaze [30-32]. MacLellan and Patla found that step width and length increased on a mediumdensity foam surface [28]. These adaptations increase the base of support and provide better control of the COM. The results of the present study demonstrated that the step widths on the compliant and rubber flooring were significantly narrower than that on the standard flooring. However, there were no statistically significant differences in the step lengths of the dominant leg on the three flooring types. The step length of the non-dominant leg on the rubber flooring was shorter than that on the selected compliant flooring and the standard flooring. The gait velocity and the COM velocity of the compliant flooring were also not significantly different to those of the standard flooring. It can therefore be concluded that no conservative walking pattern was demonstrated on the rubber flooring and the compliant flooring.

Walking on an uneven terrain is more energetically costly than walking on smooth ground. Voloshina et al. found an increase in the hip- and knee-joint muscle activities and work performance on an uneven surface relative to a smooth surface [33]. MacLellan and Patla also found an increase in gastrocnemius and soleus activity during push-off, accounting for the increases in step length seen on the compliant surface in the current study [28]. The present study found that the vertical GRFs for the three flooring types were not statistically different for both legs for the three events of initial contact, loading response and terminal stance. However, in the toe off phase, there were lower vertical GRFs on the compliant flooring and rubber flooring than on the standard flooring, which may be the result of their superior shock-absorption properties. The horizontal force had a negative phase during the first half of the stance, indicating the presence of a backward, horizontal, frictional force acting between the ground and the foot. This force may prevent an individual from slipping while walking on a slippery floor [34]. In addition, this study found that there were higher peak posterior and anterior GRFs on the standard flooring than on the compliant and rubber flooring for both legs. The lower the posterior GRF, the more slippery an event may be. However, the differences in the values were very small (0.01-0.04 N/ $\mathrm{kg}$ ), which would not have a significant clinical impact.

The major strength of this study is that it included a large number of participants to detect statistically significant levels of difference. The authors studied the selected compliant flooring and compared the results with those of the rubber and the standard flooring (the rigid force plate, which represented the common residential flooring type).

However, the study also had several limitations. Firstly, the gait speed was not controlled as we considered that doing so might influence gait parameters such as step width, step length, or velocity. However, with a self-comfortable speed, patients could walk with a more natural pattern without needing to be concerned about their pace. Secondly, all participants were healthy, older people who did not have any walking problems. Therefore, we do not know the effect of the compliant or the rubber flooring on the balance and other gait parameters of younger people or on patients who have some walking difficulties. There was some gender difference of the data (38 females and 26 males). A gender population controlled should be considered in our future study. Thirdly, there was a limitation in the arrangement of the force plate during the walking tests. Having a number of force plates placed consecutively over the full length of the walking route instead of having only 2 plates placed centrally would have allowed us to collect force data during consecutive steps and therefore to analyze simultaneous work. Finally, we selected one popular compliant flooring, however, it may not represent all other compliant floorings. 


\section{Conclusion}

In conclusion, the compliant flooring demonstrated no differences from the rubber and standard flooring in terms of balance and stability for elderly people in both the vertical and antero-posterior axes. For both legs, there were lower vertical GRFs at the toe-off phase and lower anterior-posterior GRFs for the compliant and rubber flooring than for the standard flooring. The selected compliant flooring may be a safe flooring that can be used to adjust the environmental factor in order to reduce the risk of falls by the elderly.

\section{Acknowledgements}

This work was supported by SCG Cement-Building Materials Co., Ltd. The authors gratefully acknowledge Miss Suchitphon Chanchoo for data collection and statistical analysis, Miss Waraporn Chalermsuk for manuscript preparation, and Mr. David Park for thoroughly proofreading the manuscript.

\section{References}

1. Blake AJ, Morgan K, Bendall MJ, Dallosso H, Ebrahim SB, et al. (1988) Falls by elderly people at home: prevalence and associated factors. Age Ageing 17: 365-372. [crossref]

2. Campbell AJ, Reinken J, Allan BC, Martinez GS (1981) Falls in old age: a study of frequency and related clinical factors. Age Ageing 10: 264-270. [crossref]

3. Prudham D, Evans JG (1981) Factors associated with falls in the elderly: a community study. Age Ageing 10: 141-146. [crossref]

4. Downton JH, Andrews K (1991) Prevalence, characteristics and factors associated with falls among the elderly living at home. Aging (Milan, Italy) 3: 219-228. [crossref]

5. Stalenhoef PA, Diederiks JP, Knottnerus JA, Kester AD, Crebolder HF (2002) A risk model for the prediction of recurrent falls in community-dwelling elderly: a prospective cohort study. J Clin Epidemiol 55: 1088-1094. [crossref]

6. Tinetti ME, Speechley M, Ginter SF (1988) Risk factors for falls among elderly persons living in the community. N Engl J Med 319: 1701-1707. [crossref]

7. Assantachai P, Praditsuwan R, Chatthanawaree W, Pisalsarakij D, Thamlikitkul V (2003) Risk factors for falls in the Thai elderly in an urban community. J Med Assoc Thai 86: 124-130. [crossref]

8. Organization WH (2007) WHO global report on falls prevention in older age. World Health Organization. 2015: 1-7.

9. Lachance CC, Jurkowski MP, Dymarz AC, Mackey DC (2016) Compliant flooring to prevent fall-related injuries: a scoping review protocol. BMJ Open 6: e011757. [crossref]

10. Lachance CC, Jurkowski MP, Dymarz AC, Robinovitch SN, Feldman F, et al. (2017) Compliant flooring to prevent fall-related injuries in older adults: A scoping review of biomechanical efficacy, clinical effectiveness, cost-effectiveness, and workplace safety. PloS one 12: e0171652. [crossref]

11. Simpson AH, Lamb S, Roberts PJ, Gardner TN, Evans JG (2004) Does the type of flooring affect the risk of hip fracture? Age Ageing 33: 242-246. [crossref]

12. Drahota AK, Ward D, Udell JE, Soilemezi D, Ogollah R, Higgins B, et al. (2013) Pilot cluster randomised controlled trial of flooring to reduce injuries from falls in wards for older people. Age and ageing 42: 633-640. [crossref]

13. Warren CJ, Hanger HC (2013) Fall and fracture rates following a change from carpet to vinyl floor coverings in a geriatric rehabilitation hospital. A longitudinal, observational study. Clin Rehabil 27: 258-263. [crossref]

14. Hoffmann TC, Glasziou PP, Boutron I, Milne R, Perera R, et al. (2014) Better reporting of interventions: template for intervention description and replication (TIDieR) checklist and guide. BMJ 348: g1687. [crossref]

15. Adli H, Ismail KA (2012) Coefficient of restitution of sports balls: A normal drop test. IOP Conference Series: Materials Science and Engineering 36: 012038.

16. Cross R (2000) The coefficient of restitution for collisions of happy balls, unhappy balls, and tennis balls. Am J Phys 68: 1025-1031. [crossref]

17. Kadaba MP, Ramakrishnan HK, Wootten ME (1990) Measurement of lower extremity kinematics during level walking. J Orthop Res 8: 383-392. [crossref]

18. Oates AR, Frank JS, Patla AE (2010) Control of dynamic stability during adaptation to gait termination on a slippery surface. Exp Brain Res 201: 47-57. [crossref]

19. Winter DA (2009) Biomechanics and motor control of human movement (4 $4^{\text {th }}$ edn). Hoboken: Wiley pp: 370.
20. van Melick N, Meddeler BM, Hoogeboom TJ, Nijhuis-van der Sanden MWG, et al. (2017) How to determine leg dominance: The agreement between self-reported and observed performance in healthy adults. PLoS One 12: e0189876. [crossref]

21. Faul F, Erdfelder E, Buchner A, Lang AG (2009) Statistical power analyses using G*Power 3.1: tests for correlation and regression analyses. Behav Res Methods 41: 1149-1160. [crossref]

22. Reinsch S, MacRae P, Lachenbruch PA, Tobis JS (1992) Attempts to prevent falls and injury: a prospective community study. Gerontologist 32: 450-456. [crossref]

23. Swift CG, Iliffe S (2014) Assessment and prevention of falls in older people-concise guidance. Clin Med (Lond) 14: 658-662. [crossref]

24. Thiamwong L, Thamarpirat J, Maneesriwongul W, Jitapunkul S (2008) Thai falls risk assessment test (Thai-FRAT) developed for community-dwelling Thai elderly. J Med Assoc Thai 91: 1823-1831. [crossref]

25. Lord SR, Menz HB (2000) Visual contributions to postural stability in older adults. Gerontology 46: 306-310. [crossref]

26. Marigold DS, Patla AE (2005) Adapting locomotion to different surface compliances: neuromuscular responses and changes in movement dynamics. $J$ Neurophysiol 94: 1733-1750. [crossref]

27. Marigold DS, Patla AE (2002) Strategies for dynamic stability during locomotion on a slippery surface: effects of prior experience and knowledge. $J$ Neurophysiol 88: 339-353. [crossref]

28. MacLellan MJ, Patla AE (2006) Adaptations of walking pattern on a compliant surface to regulate dynamic stability. Exp Brain Res 173: 521-530. [crossref]

29. Murray MP, Kory RC, Clarkson BH (1969) Walking patterns in healthy old men. $J$ Gerontol 24: 169-178. [crossref]

30. Marigold DS, Patla AE (2008) Age-related changes in gait for multi-surface terrain. Gait Posture 27: 689-696. [crossref]

31. Menant JC, Perry SD, Steele JR, Menz HB, Munro BJ, et al. (2008) Effects of shoe characteristics on dynamic stability when walking on even and uneven surfaces in young and older people. Arch Phys Med Rehabil 89: 1970-1976. [crossref]

32. Menz HB, Lord SR, Fitzpatrick RC (2003) Acceleration patterns of the head and pelvis when walking on level and irregular surfaces. Gait Posture 18: 35-46. [crossref]

33. Voloshina AS, Kuo AD, Daley MA, Ferris DP (2013) Biomechanics and energetics of walking on uneven terrain. J Exp Biol 216: 3963-3970. [crossref]

34. Marasovi TEA, Ceci M, Zanchi V (2009) Analysis and Interpretation of Ground Reaction Forces in Normal Gait. WSEAS TRANSACTIONS on SYSTEMS 8. 1105 1114 .

\section{Citation:}

Ganokroj P, Limroongreungrat W, Kerdsomnuek P, Riansuwan K, Keyurapan E, Wang YT and Vanadurongwan B (2018) Does flooring-type change the gait characteristics of the older adult? Analysis of balance and temporalspatial gait parameters and ground reaction force. Ageing Sci Ment Health Stud Volume 2(3): 1-8. 